\title{
A INTERFERÊNCIA DA PRODUÇÃO DE LEITE NAS TAXAS DE RECUPERAÇÃO OOCITÁRIA E CONVERSÃO EM EMBRIÕES DE DOADORAS DAS RAÇAS GIR E MEIO SANGUE
}

\author{
(The interference of milk production in oocytes recovery rates and conversion in \\ embryos of Gyr and Gyr-crossbred)
}

Victor Henrique Miquelanti ${ }^{1}$, Carlos Renato de Freitas Guaitolini², Eduardo Trevisol ${ }^{3}$, André Maciel Crespilho ${ }^{4}$, Rosiara Rosária Dias Maziero ${ }^{1 *}$

\footnotetext{
1 Universidade Paranaense, Umuarama, Paraná, Brasil; ${ }^{2}$ Faculdade de Medicina Veterinária e Zootecnia da Universidade Estadual de São Paulo, Botucatu, São Paulo, Brasil; ${ }^{3}$ In Vitro Brasil, Mogi Mirim, São Paulo, Brasil; ${ }^{4}$ Universidade Santo Amaro, São Paulo, São Paulo, Brasil.

*Corresponding author: rosiaramaziero@prof.unipar.br
}

RESUMO - Este estudo teve por objetivo avaliar a interação entre a produção de leite e a taxa de recuperação oocitária, produção in vitro de embriões e conversão oócito-embrião de doadoras da raça Gir, Girolando 1/2 sangue e Girolando 5/8. Para o estudo foram utilizadas 150 vacas doadoras de oócitos, selecionadas com base em seu mérito genético. Destas, 50 fêmeas da raça Gir (Bos taurus indicus), 60 fêmeas Girolando 1/2 sangue (1/2 Bos taurus taurus $\times 1 / 2$ Bos taurus indicus) e 40 Girolando 5/8 (5/8 Bos taurus taurus $\times 3 / 8$ Bos taurus indicus). A raça Gir apresentou recuperação oocitária inferior às demais avaliadas (Gir 17,5 $\pm 11,3 \times$ Girolando 1/2 sangue 23,8 $\pm 15,0 \times$ Girolando 5/8 24,8 $\pm 11,7)(P<0,05)$. Porém, 0 percentual de conversão em blastocistos mostrou ser superior, apesar de não apresentar diferença significativa na quantidade de embriões produzidos (Gir 29,1\% $x$ Girolando $1 / 2$ sangue 27,7\% x Girolando 5/8 18,5\%) (P>0,05). Não houve interação entre a produção de leite e o genótipo da doadora $(P>0,05)$. Entretanto, foi observado uma elevação na recuperação de oócitos e produção de embriões, com a progressão da curva de lactação nas raças Gir e Girolando 1/2 sangue. Por outro lado, as Girolando 5/8 apresentaram diminuição na recuperação de oócitos e conversão em embriões conforme aumento da produção leiteira. Assim, concluiu-se que produção de leite das matrizes não interferiu nos índices de recuperação de oócitos, tampouco na conversão em embriões. Entretanto, várias lacunas precisam ser preenchidas para melhor compreensão das características reprodutivas, principalmente de animais cruzados.

Palavras-chave: blastocistos; lactação; oócitos; vacas.

ABSTRACT - This study aimed to evaluate the interaction between milk production and oocyte recovery rate, in vitro embryo production and oocyte-embryo conversion of Gir, Gyrolando 1/2 blood and Gyrolando 5/8 donors. For the study, 150 oocyte donor cows were selected, based on their genetic merit. Of these, 50 Gyr, Gyrolando females (Bos taurus indicus), 60 females Gyrolando 1/2 blood (1/2 Bos taurus taurus x 1/2 Bos taurus indicus) and 40 Girolando 5/8 (5/8 Bos taurus taurus $\times 3 / 8$ Bos taurus indicus). The Gyr breed presented lower oocyte recovery than the others evaluated (Gyr $17.5 \pm 11.3$ x Gyrolando 1/2 blood $23.8 \pm 15.0$ x Gyrolando $5 / 824.8 \pm 11.7)(P<0.05)$. However, the percentage of blastocyst conversion was higher, although there was no significant difference in the number of embryos produced (Gyr 29.1\% x Girolando 1/2 blood 27.7\% x Gyrolando 5/8 18.5\%) (P> 

embriões de doadoras das raças Gir e meio sangue

0.05). There was no interaction between milk production and donor genotype $(P>$ 0.05). However, an increase in oocyte recovery and embryo production was observed, with the progression of the lactation curve in the Gyr and Gyrolando 1/2 blood. Gyrolando 5/8 showed a decrease in oocyte recovery and embryo conversion as milk production increased. Thus, it were concluded that milk production of the matrices did not interfere in oocyte recovery rates, nor in embryo conversion. However, several gaps need to be filled in for a better understanding of reproductive traits, especially crossbred animals.

Keywords - blastocyst; cows; lactation; oocytes. 


\section{INTRODUÇÃO}

A pecuária leiteira apresenta grande importância para o fornecimento de alimentos, geração de emprego e renda. Para manter níveis adequados de produção se fazem necessárias biotecnologias, para tornar os sistemas de criação mais eficientes, fornecendo adequado aporte nutricional e sanitário, para cada fase da vida do animal, além de melhoramento genético constante (Duarte, 2016).

Entretanto, nos últimos 50 anos relata-se queda na taxa de concepção das vacas Holandesas (Marinho et al., 2015). Deste modo, é amplamente aceito que o principal fator envolvido no declínio da fertilidade é o balanço energético negativo pós-parto, devido a priorização de nutrientes, para maximizar a produção de leite (Leroy et al., 2008). Assim, o equilíbrio entre a produção de leite e o desempenho reprodutivo é indispensável para o melhoramento genético destes animais. Além de ser fundamental para a utilização das biotecnologias da reprodução, como a produção in vitro de embriões e a transferência de embriões (TE) bovinos (Hutchinson et al., 2013).

Associado a isto, nos períodos ou regiões com temperatura média elevada, as taxas de prenhez resultantes de inseminação artificial (IA) são geralmente menores (Ferreira, 2013). Para superar este problema, autores relatam que as TEs são efetivamente mais empregadas, pela maior resistência dos embriões, a períodos de estresse térmico, do que os gametas (Chebel et al., 2008). Assim, em áreas tropicais existe crescente interesse no cruzamento entre as raças Bos taurus (Holandês) e Bos indicus (Gir), pela sua maior capacidade de adaptação, produção leiteira e maior eficiência reprodutiva (Marinho et al., 2015).

Com base nisso, a produção in vitro de embriões (PIVE) bovinos vem sendo utilizada em escala comercial, por, dentre outras vantagens, permitir um melhor aproveitamento de fêmeas de mérito genético superior e nesse contexto, o Brasil se destaca em escala global, produzindo praticamente a metade de todos os embriões frutos de PIVE de todo o Mundo, e com perspectiva de crescimento (Cristina, 2008).

Entretanto, diversos fatores influenciam nas taxas de recuperação oocitária e conversão em embrião, como o genótipo da doadora, categoria, idade, estágio do ciclo estral, nutrição, sanidade, sazonalidade (Mello et al., 2017). Sabe-se que fêmeas Bos taurus indicus apresentam maior número de folículos recrutados por onda de crescimento folicular em comparação a fêmeas Bos taurus taurus (Pontes et al., 2010). Autores sugerem maior concentração de IGF-I (fator de crescimento semelhante a insulina) em fêmeas zebuínas, mesmo em baixa concentração de FSH (hormônio folículo estimulante) (Grazia et al., 2012). Isto interfere diretamente na eficácia de aspiração folicular guiada por ultrassonografia (OPU - ovum pick up) em fêmeas Bos taurus indicus (Mello et al., 2017).

A influência da nutrição também pode afetar diretamente na eficácia de desenvolvimento oocitário e conversão embrionária. Autores mostram que ocorrem alterações no metabolismo e fisiologia de fêmeas com excesso ou falta de nutrição, principalmente em vacas leiteiras de alta produção (Torres et al., 2015). Animais com alto consumo de matéria seca (MS) apresentam maior fluxo sanguíneo hepático, local onde existe grande metabolização de hormônios esteroides (progesterona e estradiol). Assim, estes animais apresentam menores concentrações sanguíneas destes hormônios (Mello et al., 2017). 
Assim, o objetivo do presente trabalho foi avaliar a interação entre a produção de leite e a taxa de recuperação oocitária, produção in vitro de embriões e conversão oócitoembrião de doadoras da raça Gir, Girolando 1/2 sangue e Girolando 5/8.

\section{MATERIAL E MÉTODOS}

\section{Doadoras}

O presente estudo foi realizado com 150 animais, alojados em fazenda na região de Passos, MG, Brasil (Latitude 20 43'08'S e Longitude $\left.46^{\circ} 36^{\prime} 35^{\prime \prime} \mathrm{W}\right)$. Foram utilizadas fêmeas adultas, com idade entre 3 a 5 anos, multíparas, com escore de condição corporal médio de $3,1 \pm 0,2$ (escala de 0-5; 5 obeso), não gestantes, ciclando e em lactação (média de $95 \pm 1,2$ dias).

Os animais permaneceram em pastagem (Tifton - Cynodon spp) recebendo suplementação mineral (Bovigold® - DSM - Tortuga, São Paulo, SP), ração balanceada nutricionalmente (milho e farelo de soja) e silagem (sorgo e milho), suficiente para atender as exigências nutricionais de gado leiteiro em lactação (relação volumoso: concentrado 60:40; NDT -nutrientes digestíveis totais- $65 \%$, Proteína $20 \%$, minerais $3 \%$ ).

Dentre os 150 animais foram selecionadas 50 doadoras da raça Gir, 60 Girolando 1/2 sangue e 45 Girolando $5 / 8$. As matrizes foram selecionadas com base em seu mérito genético e características fenotípicas próprias de cada raça.

As vacas encontravam-se em média de $95 \pm 1,2$ dias em lactação, com produção média de $29,8 \pm 3,2 \mathrm{Kg}$ / dia e foram divididas de acordo com a faixa de produção leiteira:

- Doadoras Gir: $4000 \mathrm{Kg}(\mathrm{n}=17) ; 5000$ $\mathrm{Kg}(\mathrm{n}=18) ; 6000 \mathrm{Kg}(\mathrm{n}=15)$;

- Doadoras Girolando 1/2 sangue: 5000 $\mathrm{Kg}(\mathrm{n}=21) ; 6000 \mathrm{Kg}(\mathrm{n}=18) ; 7000 \mathrm{Kg}$ $(\mathrm{n}=21)$;
- Doadoras Girolando 5/8: $5000 \mathrm{Kg}$ $(\mathrm{n}=15) ; 6000 \mathrm{Kg}(\mathrm{n}=15) ; 7000 \mathrm{Kg}(\mathrm{n}=$ 15).

\section{Preparo das doadoras}

Não foi utilizado protocolo hormonal prévio nos animais. Os embriões foram produzidos no laboratório comercial, localizado na cidade de Mogi Mirim, São Paulo (Latitude $22^{\circ} 25^{\prime} 55^{\prime \prime} \mathrm{s}$ e Longitude $\left.46^{\circ} 57^{\prime} 28^{\prime \prime}\right)$.

Antes de cada aspiração, o técnico retirou as fezes do reto dos animais e higienizou a região do períneo. Com o intuito de neutralizar os movimentos peristálticos e diminuir 0 desconforto, foi realizado anestesia peridural nas vacas $(2 \mathrm{~mL}$ de lidocaína com xilazina, BLOC, J.A Saúde Animal, Patrocínio Paulista, SP, Brasil).

\section{Aspiração folicular}

Cada folículo visível foi puncionado utilizando aparelho de ultrassom (DP-2200 Vet, Mindray, Shenzhen, China), transdutor micro convexo de $8 \mathrm{MHz}$ acoplado a uma guia para aspiração folicular transvaginal WTA $®$ (Watanabe Tecnologia Aplicada Ltda, Cravinhos, SP, Brasil) e mandril de aço inox.

A aspiração folicular foi realizada por cateter intravenoso descartável de 18 Gauge conectado a um tubo cônico tipo Falcon de $50 \mathrm{ml}$ por um tubo de silicone $(0,8 \mathrm{~mm})$. A punção foi conduzida por uma bomba de vácuo (WTA®) com uma pressão negativa de $100 \mathrm{~mm}$ de mercúrio. O meio de coleta utilizado foi solução tampão fosfato (DPBS, Nutricell囚, Campinas, SP, Brasil) acrescido de heparina sódica.

\section{Produção in vitro de embriões}

Logo após a punção, o material aspirado foi filtrado e lavado. Os oócitos recuperados, foram transferidos para placas de Petri, de poliestireno, de 60 
$\mathrm{mm}$ de diâmetro e classificados, com auxílio de um microscópio estereoscópio (lupa) com luz e aumento de 40 a 80 vezes. As estruturas recuperadas foram classificadas de acordo com a quantidade e morfologia das células do complexo cumulus oophorus em graus variáveis de I a IV (graus I e II= melhor qualidade, grau $\mathrm{II}=$ menor qualidade $\mathrm{e}$ grau IV= degenerado ou atrésico), de acordo com Seneda et al. (2002).

$\mathrm{Em}$ seguida, as estruturas seguiram para o laboratório comercial de produção in vitro de embriões, em equipamento de transporte (WTA®) junto ao meio de maturação (MIV) comercial da empresa, a 38,5 $\mathrm{C}^{\circ}$, atmosfera saturada com $5 \%$ de $\mathrm{CO}_{2}, 5 \%$ de $\mathrm{O}_{2}$ e $90 \%$ de nitrogênio. No laboratório a maturação prosseguiu em estufa a 38,5 $\mathrm{C}^{\circ}$, atmosfera saturada com $5 \%$ de $\mathrm{CO}_{2}, 5 \%$ de $\mathrm{O}_{2}$ e $90 \%$ de nitrogênio, até totalizar 24 horas após o término da aspiração.

Para a fertilização in vitro (FIV) utilizou-se sêmen de um único touro da raça Holandês (diferentes partidas de congelação), descongelado por 30 segundos em banho-maria a $36 \mathrm{C}^{\circ}$. Para a separação dos espermatozoides viáveis, realizou-se centrifugação em gradiente de Percoll (Maziero et al., 2016) e os oócitos foram incubados por 20 horas, em gotas de $10 \mu \mathrm{L}$ com meio FIV (comercial da empresa), contendo até 30 oócitos/gota.

Após a fecundação (FIV), os embriões foram cultivados (CIV) em meio SOFaa, em incubadora com condições de temperatura e atmosfera semelhantes à MIV e FIV, por 7 dias, até atingirem o estádio de blastocisto e se tornarem aptos a serem transferidos nas receptoras sincronizadas.

\section{ANÁLISE ESTATÍSTICA}

Os dados foram analisados utilizando 0 teste de Kruskal-Wallis (software Statisticsx9®, Nova York, EUA), uma análise de variância não paramétrica para amostras independentes dos dados de recuperação oocitária e conversão em embriões. Realizou-se também o teste ANOVA, uma análise de variância, para as diferentes taxas de produção leiteira e sua interferência na recuperação de oócitos e conversão em embriões. Os dados foram apresentados como média e desvio padrão. Para todas as análises foi adotado o nível de significância de 5 $\%$.

\section{RESULTADOS}

$\mathrm{Na}$ Tabela 1, encontram-se apresentadas as médias e desvio padrão dos oócitos recuperados, embriões produzidos e o percentual de conversão oócito-embrião de acordo com a raça e genótipo das doadoras. Verificamos menor taxa de recuperação oocitária em fêmeas da raça Gir (17,5 \pm $11,3)$, comparado a vacas Girolando 1/2 sangue $(23,8 \pm 15,9)$ e Girolando 5/8 $(24,8 \pm 11,7)$.

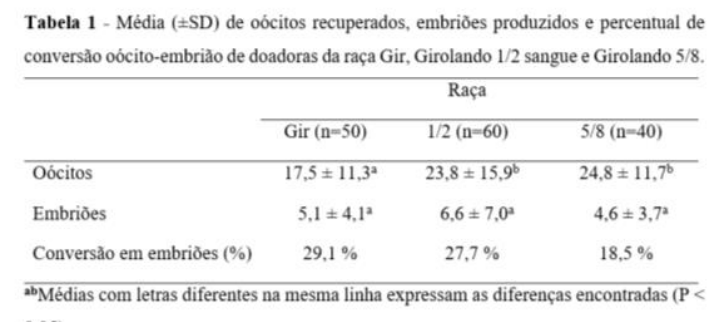

0,05 ).

Nas tabelas 2, 3 e 4 apresentamse os dados referentes a média e desvio padrão da recuperação oocitária, embriões produzidos e o percentual de conversão oócito-embriões de doadoras Gir, Girolando 1/2 sangue e Girolando $5 / 8$, respectivamente, de acordo com o genótipo e faixa de produção de leite ao longo de uma curva de lactação de 305 dias.

Não foi observada interferência da produção leiteira na recuperação de oócitos, produção de embriões e conversão oócitos em embriões, entre as diferentes raças $(P>0,05)$. 
Tabela 2 - Média ( $(\mathrm{SD})$ de oócitos recuperados, embriões produzidos e percentual de conversão oócito-embrião, de acordo com a faixa de produção leiteira (305 dias de lactação) de doadoras da raça Gir.

\begin{tabular}{lccc}
\hline & \multicolumn{3}{c}{ Faixa de produção leiteira } \\
\cline { 2 - 4 } Oócitos & $4000 \mathrm{Kg}(\mathrm{n}=17)$ & $5000 \mathrm{Kg}(\mathrm{n}=18)$ & $6000 \mathrm{~kg}(\mathrm{n}=15)$ \\
Embriões & $16,5 \pm 11,9^{\mathrm{a}}$ & $17,6 \pm 10,6^{\mathrm{a}}$ & $18,1 \pm 12,2^{\mathrm{a}}$ \\
Conversão em embriões (\%) & $3,7 \pm 2,4^{\mathrm{a}}$ & $6 \pm 4,4^{\mathrm{a}}$ & $4,8 \pm 4,6^{\mathrm{a}}$ \\
abMédias com letras diferentes na mesma linha expressam as diferenças encontradas $(\mathrm{P}<$
\end{tabular}
$0,05)$.

Tabela 3 - Média ( $( \pm \mathrm{SD})$ de oócitos recuperados, embriões produzidos e percentual de conversão oócito-embrião, de acordo com a faixa de produção leiteira (305 dias de lactação) de doadoras da raça Girolando $1 / 2$ sangue.

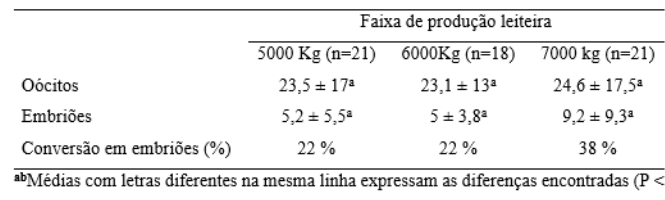
$0,05)$.

Tabela 4 - Média ( $(S D)$ de oócitos recuperados, embriões produzidos e percentual de conversão oócito-embrião, de acordo com a faixa de produção leiteira (305 dias de lactação) de doadoras da raça Girolando $5 / 8$.

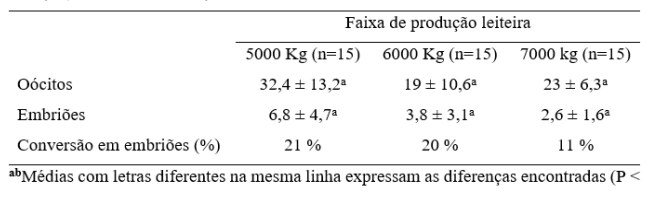
$0,05)$

\section{DISCUSSÃO}

O presente estudo avaliou a interação entre a produção de leite, taxa de recuperação oocitária, produção in vitro de embriões e conversão oócitoembrião de doadoras da raça Gir, Girolando 1/2 sangue e Girolando 5/8.

Conforme a Tabela 1 , verificamos índices médios de recuperação oocitária de 17,5 $\pm 11,3$ adequados para a raça Gir, quando comparamos aos dados obtidos por Sales et al. (2015). Estes autores relatam que obtiveram média de recuperação oocitária de 19,3 \pm 1,2 em doadoras não lactentes, com dietas de manutenção e de alta energia. Entretanto, estes autores utilizaram protocolo hormonal para sincronização da onda folicular, 5 dias antes da OPU, ou seja, folículos no início da emergência da onda folicular, sem a presença de corpo lúteo ou folículo dominante. No nosso estudo, nenhum animal teve o ciclo estral sincronizado.
Outros autores, verificaram dados similares de recuperação oocitária em doadoras Gir e Girolando 1/2 sangue, diferente do nosso estudo, em que fêmeas Gir apresentaram menor quantidade de oócitos por aspiração. Pontes et al. (2010) relatam recuperação média de 17,1 \pm 4,5 oócitos em fêmeas da raça Gir e média de 24,3 \pm 4,7 em Girolando 1/2 sangue. Estes autores especulam que a heterose promoveu um maior número de folículos e consequentemente oócitos em gados mestiços (Girolando $1 / 2$ sangue), comparado a fêmeas da raça Gir.

A produção de embriões in vitro foi igual entre as raças. Entretanto, fêmeas da raça Gir apresentaram maior conversão de oócitos em blastocistos, porém sem diferença significativa (Tabela 1). Animais zebuínos e taurinos apresentam diferenças quanto à qualidade e ao número de complexos cumulus oophorus (CCOs) recuperados por sessão de aspiração (Silva et al., 2015). Satrapa et al. (2013) e Silva et al. (2015) relatam que animais zebuínos apresentam maior quantidade de CCOs recuperados e consequentemente, maior número de embriões produzidos ao final da PIVE (Satrapa et al., 2013; Silva et al., 2015).

Autores mostram melhor eficiência de recuperação oocitária em vacas aspiradas com menor frequência, por terem um tempo maior para recuperação ovariana, após cada sessão de aspiração folicular (Viana et al., 2004). Assim, Pontes et al. (2010) afirmam que ao submeterem vacas da raça Gir, a aspirações foliculares a cada 15 dias, obtiveram taxa de conversão oócito / embrião de 18,9 \% e 17,4\% em vacas Girolando 1/2 sangue. Estes dados são inferiores ao nosso estudo, em que o intervalo entre as aspirações era de 30 dias. 
Em discordância com os nossos achados na raça Gir, Sales et al. (2015) observaram que vacas Bos indicus apresentam maior quantidade de oócitos. Por outro lado, corrobora ao relatar que os mesmos apresentam melhor qualidade para produção in vitro de embriões, em detrimento aos oócitos fornecidos por doadoras Bos taurus taurus. Estes autores relatam que genes ligados ao metabolismo celular (GLUT 1 e IGF1R) foram encontrados em abundância em embriões Bos indicus. Estes achados podem explicar, em parte, as diferenças na qualidade de oócitos e embriões entre Bos indicus e Bos taurus. A presença destes genes, interfere no transporte de glicose para as células, fundamental para 0 metabolismo energético dos oócitos e embriões (Zhou et al., 2000; Sinclair et al., 2003; Frolova e Moley, 2011).

Pupulim (2013) e Batista et al. (2014) concluíram que a população folicular está relacionada aos níveis plasmáticos de hormônio antimulleriano (AMH) que, por sua vez, é expresso por folículos antrais encontrados em maior quantidade em animais Bos taurus indicus. Além disto, autores relatam diferenças nas concentrações de insulina circulante e IGF-I (fator de crescimento semelhante a insulina) entre Bos taurus e Bos indicus, indicando maior população de folículos antrais, em vacas zebuínas (Batista et al., 2014). Nesse contexto, a maior população folicular observada em estudos anteriores para fêmeas Bos indicus, pode justificar os resultados superiores para a média de oócitos recuperados a partir de receptoras Gir em relação aos animais cruzados.

A produção de leite é utilizada tradicionalmente como o mais importante parâmetro em programas de seleção de rebanhos leiteiros. Entretanto, estudos anteriores evidenciaram que a eficiência reprodutiva declina com o aumento da produção leiteira, sendo necessário estabelecer uma relação entre genética e nutrição, para que os animais apresentem melhor conversão alimentar e manifestem seu máximo potencial produtivo (Raheja et al., 1989; Santos et al., 2018).

Autores relatam também a interferência de citocinas inflamatórias, durante infecções da glândula mamária, em vacas Bos taurus $x$ Bos taurus indicus, na composição do fluido folicular, desenvolvimento e expressão de genes específicos nos oócitos e nas células do cumulus (Bilodeu-Goeseels, 2003; Asaf et al., 2014). Citocinas próinflamatórias podem interferir negativamente na competência de desenvolvimento de oócitos, pela sua ação na composição do fluido folicular (Santos et al., 2018). Além disso, infecções na glândula mamária em animais com alta produção leiteira podem interferir na secreção de $\mathrm{GnRH}$, LH e estradiol (Herath et al., 2009). Entretanto, não foram relatados casos de mastite nos animais utilizados no presente estudo.

Corroborando com os dados apresentados na Tabela 4, Adamiak et al. (2005) relataram a diminuição no número de oócitos viáveis e das taxas de formação de blastocistos em animais de alta produção leiteira, uma vez que dietas com altos níveis energéticos acarretam em obesidade e diminuição da fertilidade das fêmeas (Armstrong et al., 2001).

Ainda se tratando das matrizes Girolando 5/8, porém com $7000 \mathrm{Kg}$ de produção leiteira, apresentaram um percentual de conversão de embriões notavelmente inferior (11\%; Tabela 4) por conta de uma maior exigência nutricional. Contudo, apesar das variações numéricas, não houve diferença significativa em função da taxa de lactação entre os grupos avaliados $(P>0,05)$. 


\section{CONCLUSÃO}

Concluiu-se que a produção de leite das matrizes não interferiu nos índices de recuperação de oócitos, tampouco na conversão em embriões. Entretanto, várias lacunas precisam ser preenchidas para melhor compreensão das características reprodutivas de animais cruzados, para ajustar melhor o manejo dos rebanhos e melhorar a eficiência das biotécnicas reprodutivas.

\section{REFERENCIAS}

ARMSTRONG, D. G.; McEVOY, T. G.; BAXTER, G. et al. Effects of dietary energy and protein on bovine follicular dynamics and embryo production in vitro: associations with the ovarian insulin-like growth factor system. Biology of Reproduction, v. 64, n. 6, p. 1624-1632, 2001.

ASAF, S.; LEITNER, G.; FURMAN, O. et al. Effects of Escherichia coli and Staphylococcus aureus-induced mastitis in lactating cows on oocyte developmental competence. Reproduction, v. 147, p. 33-43, 2014.

BATISTA, E.O.S; MACEDO, G.G; SALA, R.V. et al. Antimullerian hormone as a predictor of ovarian antral follicular population in Bos indicus (Nelore) and Bos taurus (Holstein) heifers. Reproduction in Domestic Animals, v. 49, n. 3, p. 448-452.

BILODEAU-GOESEELS, S. Effect of oocyte quality on the relative abundance of specific gene transcripts in bovine mature oocytes and 16-cell embryos. Canadian Journal of Veterinary Research, v. 67, p. 151-156, 2003.

CHEBEL, R.C.; DEMETRIO, D.G.B.; METZGER, J. Factors affecting success of embryo collection and transfer in large dairy herds. Theriogenology, v. 69, p. 98-106, 2008.
CRISTINA, F.; FERNANDES, L.; DE ALBUQUERQUE, M. Produção in vitro de embriões bovinos: estado da arte e perspectiva de uma técnica em constante evolução. Revista Brasileira de Reprodução Animal. Belo Horizonte. v.32, n.2, p.100-109, 2008.

DUARTE, V. N.; CAVALCANTI, K. A. Evolução e concentração inter-regional e intra-regional da produção de leite: 0 caso do estado de Santa Catarina no período de 2000 a 2012. EvidênciaCiência e Biotecnologia, v. 15, n. 2, p. 153-164, 2016.

FERREIRA, E. M.; VIREQUE, A. A.; ADONA, P. R. et al. Cytoplasmic maturation of bovine oocytes: structural and biochemical modifications and acquisition of developmental competence. Theriogenology, v. 71, n. 5, p. 836-848, 2009.

FERREIRA, G. Reproductive performance of dairy farms in western Buenos Aires province, Argentina. Journal of Dairy Science, v. 96, p. 8075-8080, 2013.

GARCIA, J. M.; AVELINO, K. B.; VANTINI, R. Estado da arte da fertilização in vitro em bovinos. In: Annals of the First International Symposium on Animal Reproduction Applied: 14-16 October 2004; Londrina. Faculdade de Medicina Veterinária e Zootecnia, Universidade de São Paulo, 2004. p. 223-230.

GRÁZIA, J.G.V.; GHETTI, A.M.; PAIM, C.A.S. et al. Associação da concentração de IGF plasmático e produção de oócitos e embriões em doadoras da raça Gir. Animal Reproduction, v.9, p.404, 2012.

HERATH, S.; LILLY, S.T.; FISCHER, D.P. et al. Bacterial lipopolysaccharide induces an endocrine switch from 
prostaglandin $\mathrm{F} 2 \alpha$, to prostaglandin E2 in bovine endometrium. Endocrinology, v. 150, p. 1912-1920, 2009.

HUTCHINSON, I. A.; SHALLOO, L.; BUTLER, S. T. Expanding the dairy herd in pasture-based systems: The role of sexed semen use in virgin heifers and lactating cows. Journal of Dairy Science, v. 96, p. 6742-6752, 2013.

LEROY, J. L.; VAN SOOM, M. R.; OPSOMER, I. G. F. et al. Reduced fertility in high-yielding dairy cows: Are the oocyte and embryo in danger? Part II. Mechanisms linking nutrition and reduced oocyte and embryo quality in high-yielding dairy cows. Reproduction in Domestic Animal, v. 43, p. 623-632, 2008.

MARINHO, L.S.R.; SANCHES, B.V.; ROSA, C.O. et al. Pregnancy Rates to Fixed Embryo Transfer of Vitrified IVP Bos indicus, Bos taurus or Bos indicus Bos taurus Embryos. Reproduction in Domestic Animal, v. 50 , p. $807-811$, 2015.

MAZIERO, R.R.D.; GUAITOLINI, C.R.; PASCHOAL, D.M. et al. Effect of temporary meiotic attenuation of oocytes with Butyrolactone I and Roscovitine in resistence to bovine embryos on vitrification. Reproduciton in Domestic Animal, v. 51, n. 2, p.204-11, 2016.

MELLO, R. R. C.; FERREIRA, J. E.; SOUSA, S. L. G.; MELLO, M. R. B. et al. Produção in vitro (PIV) de embriões em bovinos. Revista Brasileira de Reprodução Animal, v. 40, n. 2, p. 5864, 2017.

PONTES, J. H. F.; SILVA, K. C.; BASSO, A. C. et al. Large-scale in vitro embryo production and pregnancy rates from Bos taurus, Bos indicus, and indicus-taurus dairy cows using sexed sperm. Theriogenology, v. 74, n. 8, p. 1349-1355, 2010.
PUPULIM, A. G. R. Relação da concentração do hormônio antimulleriano com população folicular e fertilidade em fêmeas bovinas. Dissertação (mestrado) Universidade Estadual Paulista, Instituto de Biociências de Botucatu, 2013.

RAHEJA, K.L.; BURNSIDE, E.B.; SCHAEFFER, L.R. Relationships between fertility and production in Holstein dairy cattle in different lactations. Journal of Dairy Science, v.72, p.2670-2678, 1989.

SALES, J. N. S.; IGUMA, L. T.; BATISTA, R. I. et al. Effects of a highenergy diet on oocyte quality and in vitro embryo production in Bos indicus and Bos taurus cows. Journal of Dairy Science, v. 98, n. 5, p. 3086-3099, 2015.

SATRAPA, R. A.; CASTILHO, A. S.; RAZZA, E. M. et al. Differential expression of members of the IGF system in OPU-derived oocytes from Nelore (Bos indicus) and Holstein (Bos taurus) cows. Animal Reproduction Science, v. 138, p. 155-158, 2013.

SANTOS, G.; BOTTINO, M.P.; SANTOS, A.P.C. et al. Subclinical mastitis interferes with ovulation, oocyte and granulosa cell quality in dairy cows. Theriogenology, v. 119 , p. 214-219, 2018.

SENEDA, M. M.; ROBERTO, E. C.; GARCIA, J. M. Aspectos técnicos e biológicos da obtenção de oócitos bovinos: revisão de literatura. Semina: Ciências Agrárias, Londrina, v. 23, n. 1, p. 101-110, 2002.

TORRES, H.A.L.; TINEO, J.S.A.; RAIDAN, F.S.S. Influência do escore de condição corporal na probabilidade de prenhez em bovinos de corte. Archivos de Zootecnia, v.65, p.255-260, 2015. 
VIANA, J. H. M., DE ALMEIDA CAMARGO, L. S., DE MORAES FERREIRA, A. et al. Short intervals between ultrasonographically guided follicle aspiration improve oocyte quality but do not prevent establishment of dominant follicles in the Gir breed (Bos indicus) of cattle. Animal Reproduction Science, v. 84, n. 1-2, p. 1-12, 2004. 